\title{
Investigation on Microstructure and Grain Refining Performance of a New Type of Al-3Ti-1C Master Alloy
}

\author{
Vahid Hassanbeygi, Ali Shafyei \\ Department of Materials Engineering, Isfahan University of Technology, Isfahan, Iran \\ Email: v.hassanbeygi@ma.iut.ac.ir
}

Received 13 June 2014; revised 14 July 2014; accepted 12 August 2014

Copyright (C) 2014 by authors and Scientific Research Publishing Inc.

This work is licensed under the Creative Commons Attribution International License (CC BY). http://creativecommons.org/licenses/by/4.0/

c) (i) Open Access

\begin{abstract}
Grain refining process plays a significant role in preventing columnar and coarse grains and it encourages fine grain formation. Although Al-Ti-B master alloys use widely as aluminium grain refiners, there are several problems in their applications. So, this kind of master alloys use less than last. Because of great properties of Al-Ti-C refiners, they can be considered as suitable candidates for use instead of Al-Ti-B master alloys. In recent years, Al-Ti-C refiners have attracted huge attention among researchers. In this paper, Al-3Ti-1C master alloy is prepared with a melting reaction method. This method involves adding graphite powder and fine titanium particles into superheated pure aluminium. Then microstructure of this master alloy is studied by scanning electron microscope (SEM) and its phases are distinguished by energy dispersive spectroscopy (EDS). In the next part, $200 \mathrm{ppm}$ of Al-3Ti-1C master alloy is added to pure aluminium and its refining efficiency is compared with the condition in which TiC powders are added to aluminium melt directly. It is found that the fading time for both $\mathrm{Al}-3 \mathrm{Ti}-1 \mathrm{C}$ and $\mathrm{TiC}$ powder is about 15 minutes and in overall, grain refining efficiency of $\mathrm{Al}-3 \mathrm{Ti}-1 \mathrm{C}$ is more than TiC powders in 60 minutes.
\end{abstract}

\section{Keywords}

Al-Ti-C Master Alloy, Grain Size, Microstructure, Grain Refining, TiC Powder

\section{Introduction}

Grain refinement is an important technique to improve the soundness of aluminium products. Usually, master alloys add to molten metal as a grain refiner. They contain potent nucleant particles. These particles promote formation of a fine equiaxed macrostructures. The fine and equiaxed grain structure causes high toughness, high 
yield strength, excellent formability, good surface finish and improve ability to achieve a uniform anodized surface, better fatigue life and good machinability. Furthermore, a sound grain refining practice avoids hot tearing, allows a marked increase in casting speed and improves the homogeneity of cast structures by refining the distribution of secondary phases and micro porosity [1]-[6].

A lot of inactive particles are found on grain boundaries, where they have been pushed in front of the solidliquid interface, whereas active particles are found within grains [5]. In aluminium master alloys, usually TiC and $\mathrm{TiB}_{2}$ particles are nucleant and $\mathrm{TiAl}_{3}$ particles restrict the growth of $\alpha$-Al grains after they are nucleated [7]. So, fine $\mathrm{TiAl}_{3}$ particles are good [8] [9] but these particles dissolve in melt rapidly and don't have a favorable fading behavior [10]. Usually, $\mathrm{TiAl}_{3}$ phases are blocky and these blocky crystals tend to act fast, but their effects fade quickly. Sometimes $\mathrm{TiAl}_{3}$ phases have petal and plate-like structures and act more slowly, but their grain refining efficiency improves with time and lasts longer [11].

Mohanty and Gruzleski studied on Al-Ti-B master alloys and conclude that $\mathrm{TiB}_{2}$ is a poor nucleant but, it is well known that the Al-Ti-C master alloys are good refiners for Al alloys [8]. The TiC particles, present in the master alloy, remain stable in the melt and act as the active nucleant substrates. These particles are very fine and act fast but dissolve in molten aluminium rapidly. So, to improve the fading time, coarse $\mathrm{TiAl}_{3}$ particles are preferable.

The particle theory suggests that the nucleation occurs on the carbides within the master alloys [12].

The initial temperature of melt has a big effect on the reaction delay time. The lowest temperature of melt resulted in the longest delay time [13] [14].

Maxwell and Hellawell [15] suggest that the time for complete dissolution of the aluminide, being highly dependent on the size of the aluminide. In fact, proportional to the square of the particles dimension:

$$
t=10 D^{2}
$$

where $t$ is the time for complete dissolution of the aluminides and $D$ is particle size $(\mu \mathrm{m})$. They did not mention the temperature for the analysis.

\section{Experimental Procedure}

$\mathrm{Al}-\mathrm{Ti}-\mathrm{C}$ master alloys were produced from Ti powder; commercial pure $\mathrm{Al}$ and graphite powder with size less than $250 \mu \mathrm{m}$. Master alloys were prepared by a melt reaction method. In this method, commercial pure Al melted using a resistance furnace with argon protective atmosphere. When the melt temperature reached to $1200^{\circ} \mathrm{C}$, graphite and fine titanium particles added into it. The holding time was 60 min with stirring the melt every 15 minutes. Then, melt was poured into a $500^{\circ} \mathrm{C}$ preheated permanent mould. A k-type thermocouple was mounted and placed in the center of mould. The cooling rate in the mould was calculated with using a data acquisition system.

The efficiency of produced Al-3Ti-1C master alloy on grain refining, was evaluated by adding $200 \mathrm{ppm}$ of master alloy into the pure molten $\mathrm{Al}$ at $720^{\circ} \mathrm{C}$. The holding time was variable, from 5 to 120 minutes. Then, the melt poured into a permanent mould. The samples cut at a distance of $35 \mathrm{~mm}$ from the bottom surface and prepared for micro or macrostructure tests.

Also, the TiC powder with size less than $100 \mu \mathrm{m}$ was added into molten $\mathrm{Al}$ as a grain refiner and the results compared with Al-3Ti-1C master alloy. Figure 1 shows the SEM picture of TiC powders.

\section{Results and Discussions}

The cooling rate diagram shows that the solidification of master alloy is fast. The solidification complete within 130 seconds (Figure 2) and maximum cooling rate, according to the first derivative of this diagram, is $5^{\circ} \mathrm{C} / \mathrm{s}$.

Figure 3 shows $\mathrm{X}$-Ray diffraction of the Al-3Ti-1C master alloy. This figure shows that the master alloy mainly contains three phases, $\mathrm{TiC}, \mathrm{Ti}_{6} \mathrm{C}_{3.75}$ and $\mathrm{TiAl}_{3}$, embedded in $\mathrm{Al}$ matrix.

Microstructure of Al-3Ti-1C master alloy with flake-like $\mathrm{TiAl}_{3}$, TiC and $\mathrm{Ti}_{6} \mathrm{C}_{3.75}$ particles in $\mathrm{Al}$ matrix is shown in Figure 4. The EDS spectrums of the phases 1, 2 and 3 in the microstructure of master alloy are shown in Figure 5. Figure 4(a) shows that $\mathrm{TiAl}_{3}, \mathrm{Ti}_{6} \mathrm{C}_{3.75}$ and $\mathrm{TiC}$ particles are distributed in $\mathrm{Al}$ matrix uniformly. Figure 4(b) shows $\mathrm{TiAl}_{3}$ plates with above $50 \mu \mathrm{m}$ length are surrounded with lots of sub-micron size TiC and $\mathrm{Ti}_{6} \mathrm{C}_{3.75}$ particles which are disconnected. This feature is related to high melting temperature and long holding time [16]. In higher magnification, TiC particles with approximately $2 \mu \mathrm{m}$ diameters are shown (Figure 4(c)). 


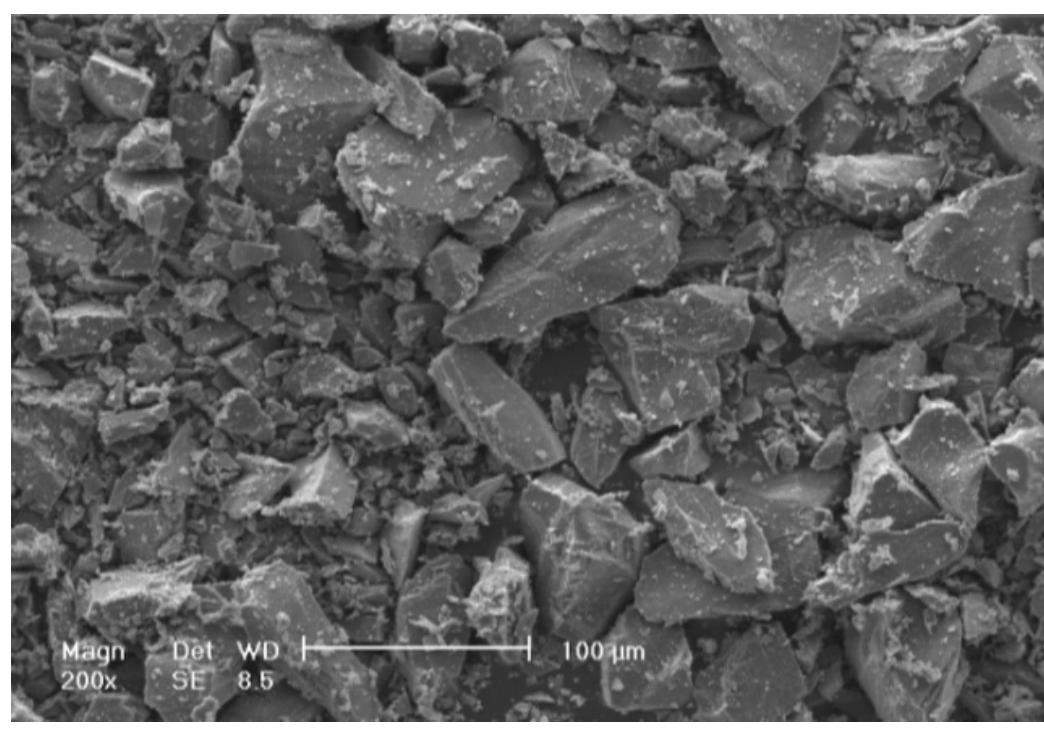

Figure 1. TiC powders that added to $\mathrm{Al}$ melt as the grain refiner.

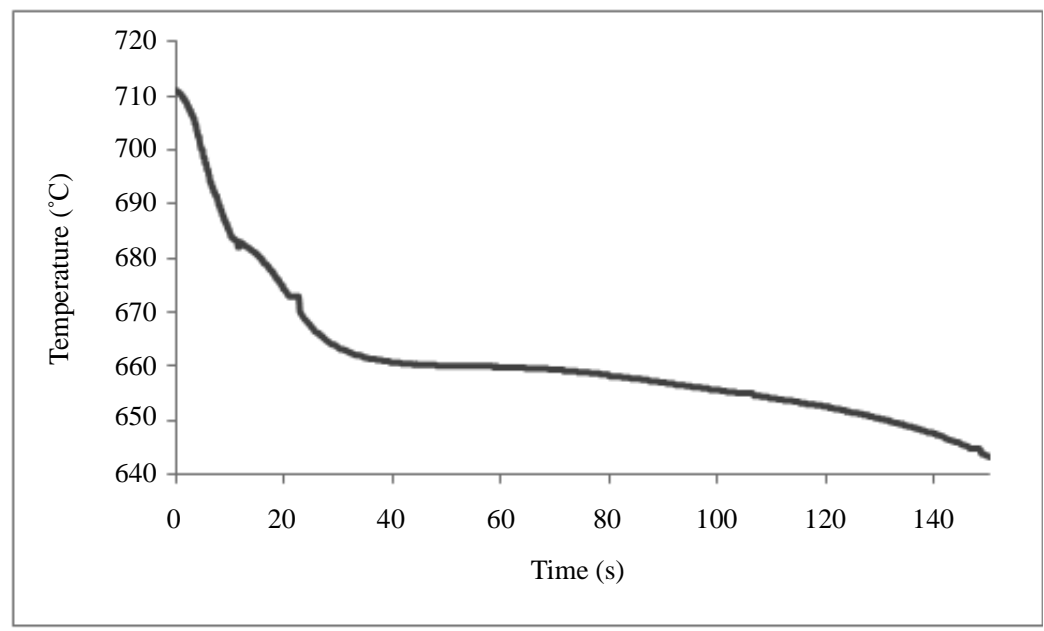

Figure 2. Cooling rate of master alloy in the permanent mould.

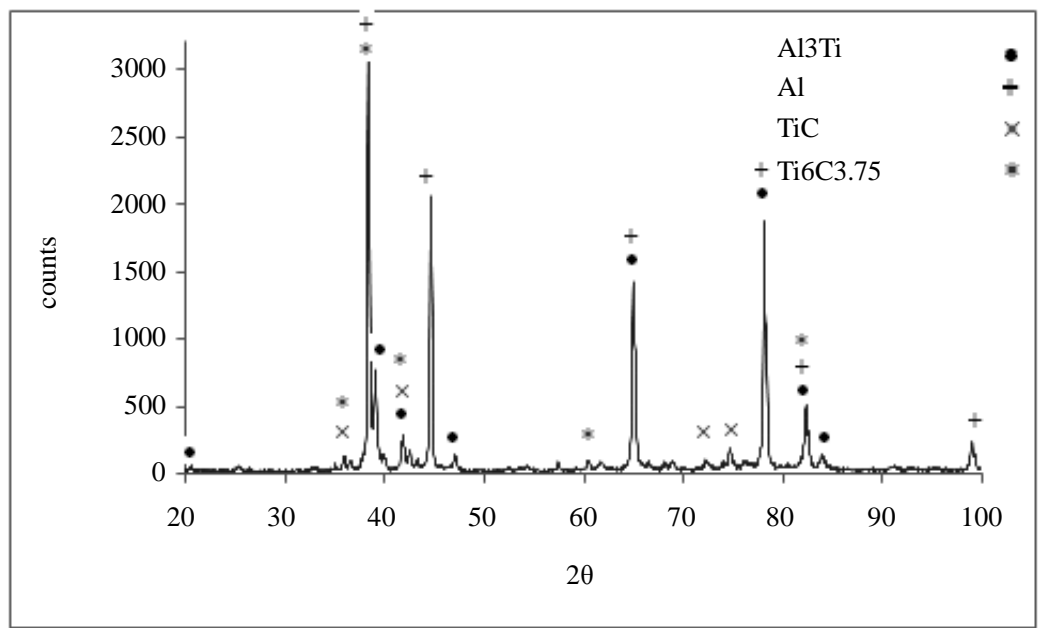

Figure 3. X-ray diffraction of Al-Ti-C that cooled in preheated permanent mould. 

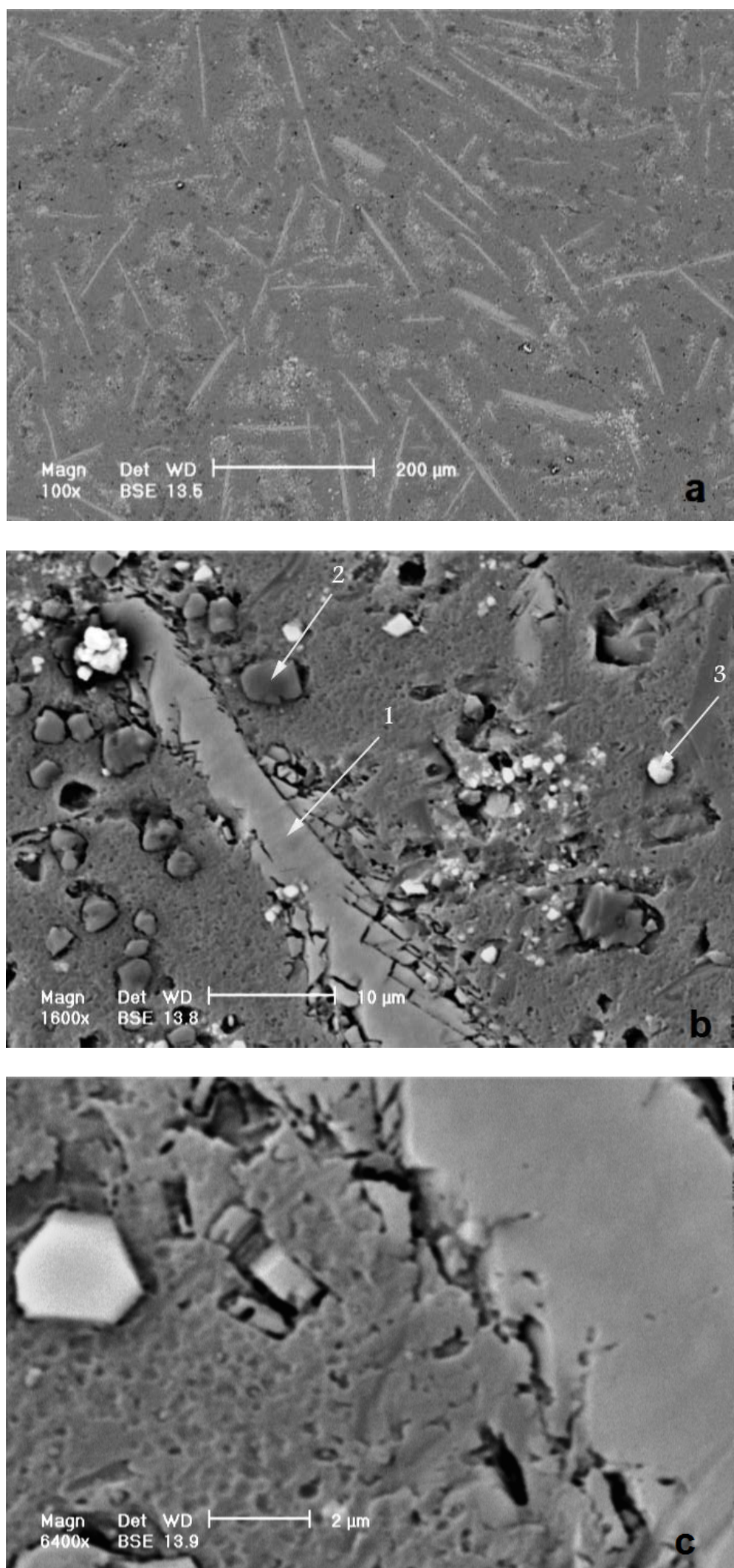

Figure 4. Microstructure of master alloy with different magnification: (a) $100 \times$; (b) $800 \times$; (c) $6400 \times$. 
The majority of the fine TiC particles are equiaxed and their surfaces are clear and regular. These have a large effect on grain refining efficiency [17].

Figure 5(a) shows the analysis of position 1 . This position has very low carbon and high titanium; thus it's $\mathrm{TiAl}_{3}$ phase. Figure 5(b) has more carbon and less titanium; this phase is $\mathrm{TiC}$ that is present in position 2. Energy dispersive X-ray analysis spectrum of position 3 is shown in Figure 5(c). This position has high amounts of carbon and titanium and its phase is $\mathrm{Ti}_{6} \mathrm{C}_{3.75}$.

Furthermore, distribution of different phases including $\mathrm{TiC}, \mathrm{TiAl}_{3}$ and $\mathrm{Ti}_{6} \mathrm{C}_{3.75}$ are shown in Figure 6. This figure shows that $\mathrm{TiAl}_{3}$ phase is more than others. $\mathrm{Ti}_{6} \mathrm{C}_{3.75}$ is a little more than $\mathrm{TiC}$ but sum of both of them is less than $\mathrm{TiAl}_{3}$. This amount of $\mathrm{TiAl}_{3}$ phase improves the fading time of $\mathrm{Al}-3 \mathrm{Ti}-1 \mathrm{C}$ master alloy.

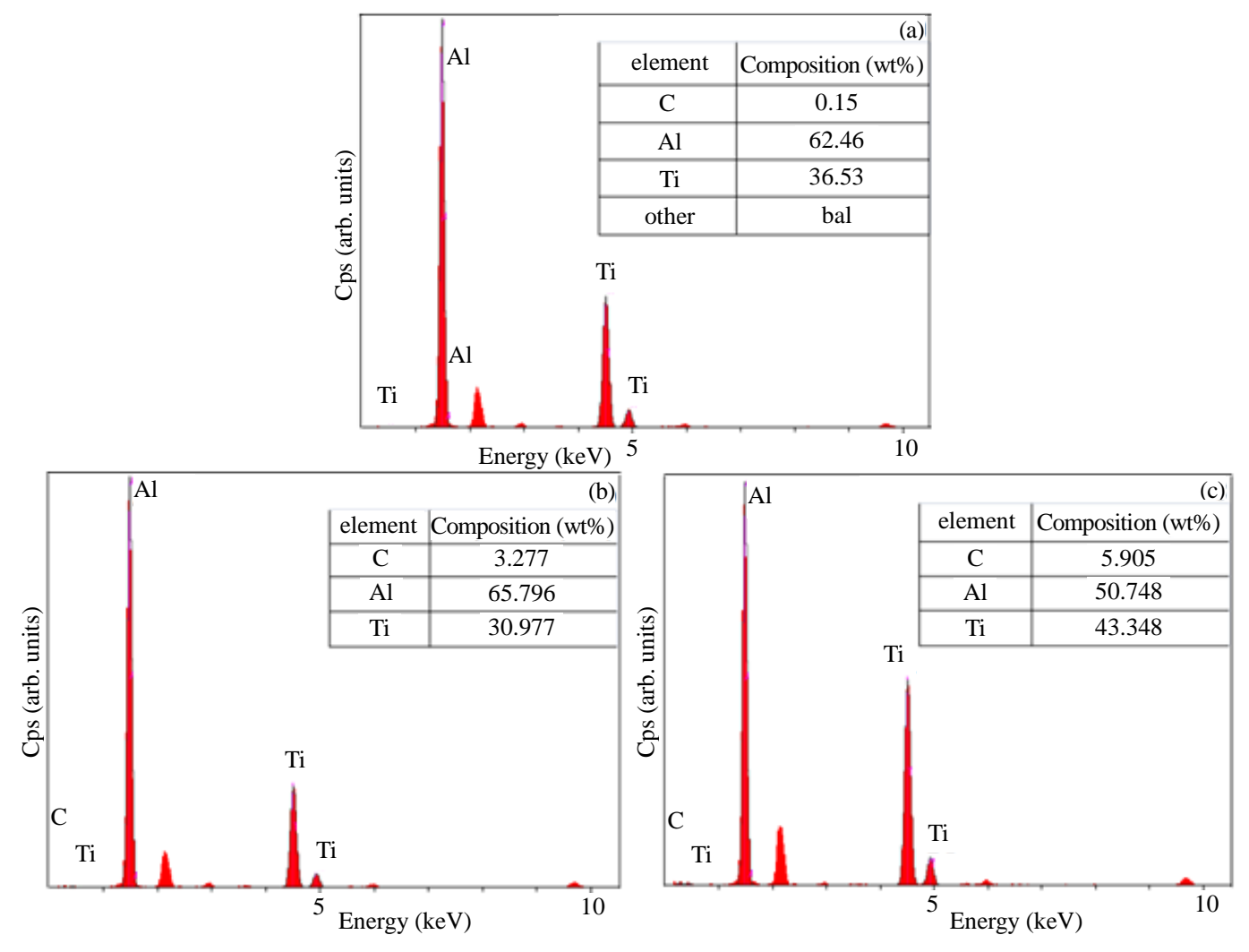

Figure 5. Energy dispersive X-ray analysis of Al-3Ti-1C master alloy in place: (a) 1; (b) 2; (c) 3 of Figure 5(b).

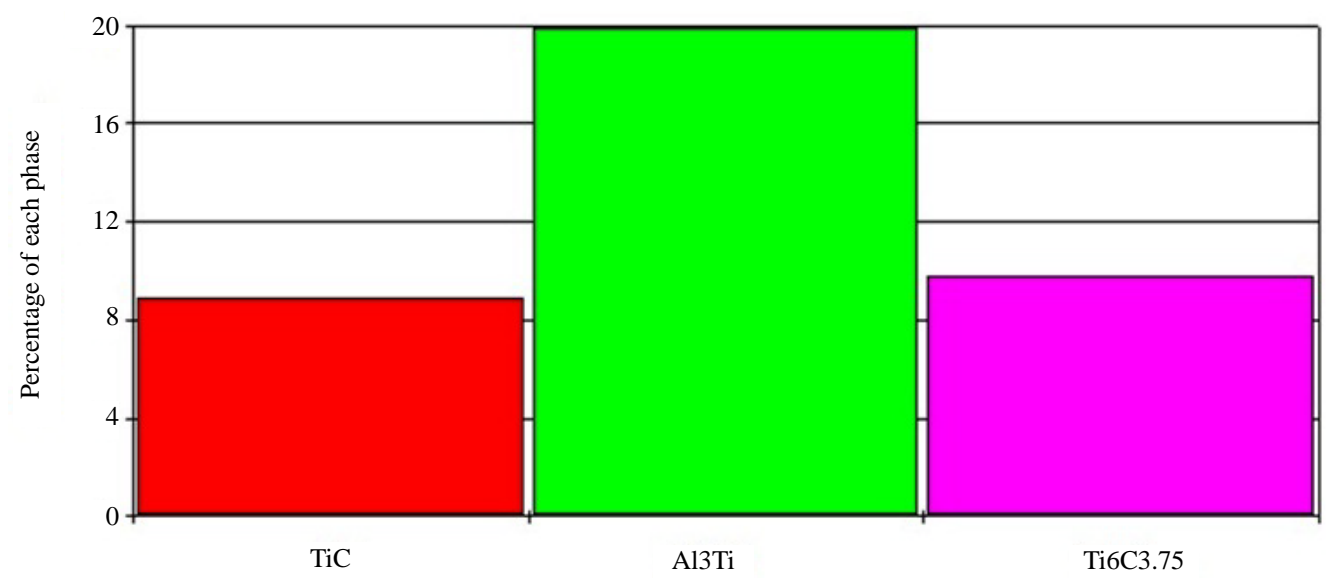

Figure 6. Distribution of different phases including $\mathrm{TiC}, \mathrm{TiAl}_{3}$ and $\mathrm{Ti}_{6} \mathrm{C}_{3.75}$. 
The macrostructure of commercial pure $\mathrm{Al}$ refined with Al-3Ti-1C master alloy is shown in Figure 7. As it can be seen, by increasing the fading time to $15 \mathrm{~min}$, the grain refining efficiency of Al-3Ti-1C master alloy has increased because of coarse shapes of $\mathrm{TiAl}_{3}$ phase. So, $\mathrm{TiAl}_{3}$ phase needs a long time for dissolution. Kori and Zhang [18] [19] reported that the fading time of Al-Ti-C master alloy is 15 min, and Al-3Ti-1C in this work has a same fading time. Fading time in this investigation is because of high temperature in producing master alloy step and coarse $\mathrm{TiAl}_{3}$ particles. This has been previously reported [20].

A compression between the efficiency of TiC powder and Al-3Ti-1C in grain refining is shown in Figure 8. The grain size was calculated from linear method. A minimum grain size is achieved in about 15 min for both TiC powder and master alloy. Overall, the ability of master alloy in refining is higher than TiC powder.
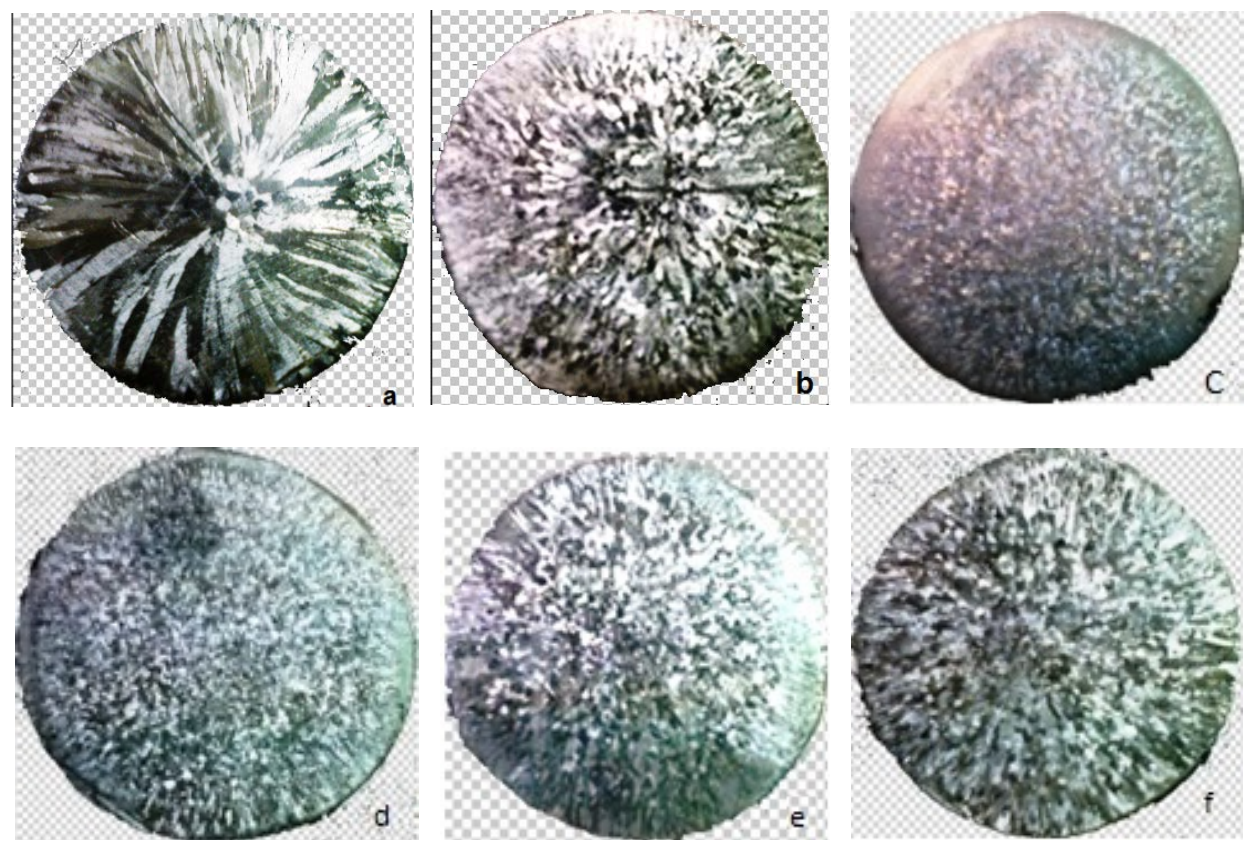

Figure 7. Macrostructure of aluminum samples, pouring temperature was $720^{\circ} \mathrm{C}$ and addition level was $200 \mathrm{ppm}$ of $\mathrm{Al}-3 \mathrm{Ti}-1 \mathrm{C}$ at different fading times; (a) without grain refiner; (b) $5 \mathrm{~min}$; (c) $15 \mathrm{~min}$; (d) $30 \mathrm{~min}$; (e) $60 \mathrm{~min}$; (f) $120 \mathrm{~min}$.

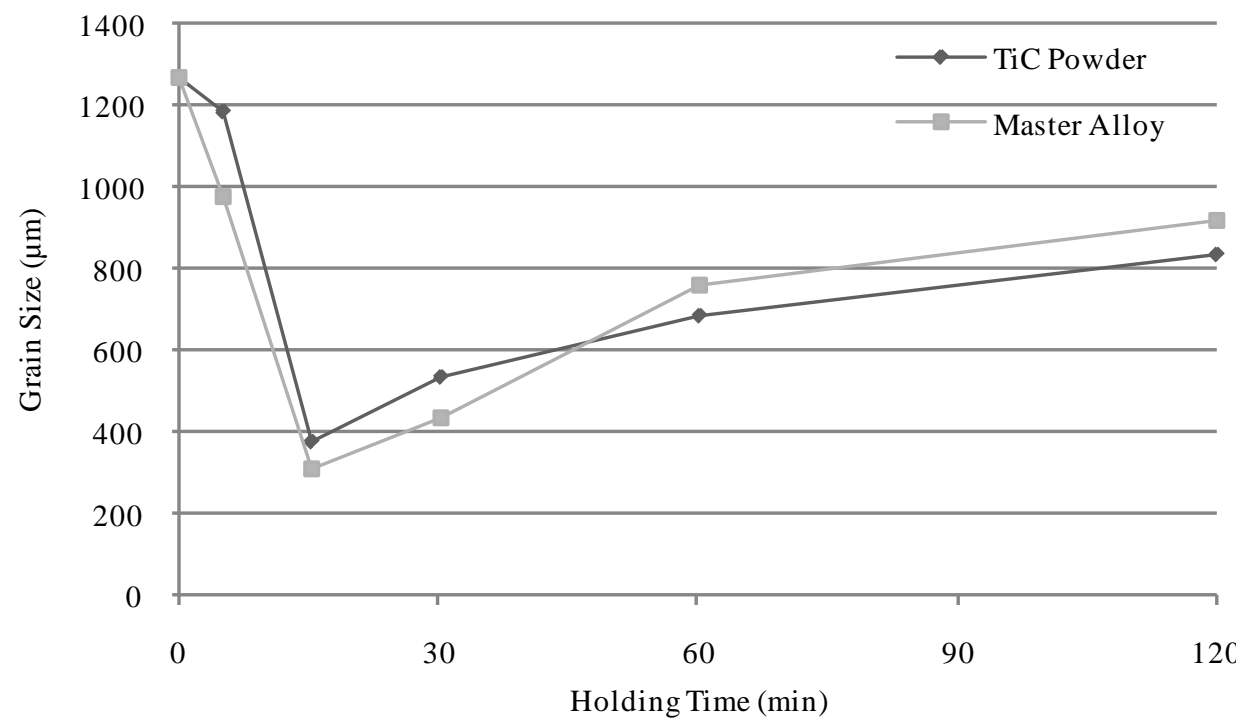

Figure 8. Variation of grain size with holding time. 


\section{Conclusions}

In Al-Ti-C master alloy, the size, surface characteristic and distribution of carbides and aluminides, as well as the morphology and size of $\mathrm{TiC}$ and $\mathrm{TiAl}_{3}$, are related to the melting temperature, holding time, etc.

The Al-Ti-C master alloy, which was manufactured at $1200^{\circ} \mathrm{C}$ and 1 hour, holding time, with narrow $\mathrm{TiAl}_{3}$, fine $\mathrm{TiC}$ and $\mathrm{Ti}_{6} \mathrm{C}_{3.75}$ phases, has a good grain refining efficiency and fading time behavior.

In this type of grain refiner, the optimum time of using is 15 minutes and in more than 60 minutes the grain refining efficiency is not good.

In overall, grain refining of $\mathrm{Al}-3 \mathrm{Ti}-1 \mathrm{C}$ master alloy is better than $\mathrm{TiC}$ powder.

\section{References}

[1] Sato, K. and Flemings, M.C. (1998) Grain Refining of Al-4.5Cu Alloy by Adding an Al-30TiC Master Alloy. Metallurgical and Materials Transactions A, 29, 1707-1710.

[2] Kashyap, K.T. and Chandrashekar, T. (2001) Effects and Mechanisms of Grain Refinement in Aluminium Alloys. Bulletin of Materials Science, 24, 345-353. http://dx.doi.org/10.1007/BF02708630

[3] Birol, Y. (2006) Effect of the Salt Addition Practice on the Grain Refining Efficiency of Al-Ti-B Master Alloys. Alloys and Compounds, 420, 207-212. http://dx.doi.org/10.1016/j.jallcom.2005.11.010

[4] Birol, Y. (2007) Production of Al-Ti-B Grain Refining Master Alloys from $\mathrm{B}_{2} \mathrm{O}_{3}$ and $\mathrm{K}_{2} \mathrm{TiF}_{6}$. Alloys and Compounds, 443, 94-98. http://dx.doi.org/10.1016/j.jallcom.2006.10.009

[5] Quested, T.E. and Greer, A.L. (2004) The Effect of the Size Distribution of Inoculant Particles on As-Cast Grain Size in Aluminium Alloys. Acta Materialia, 52, 3859-3868. http://dx.doi.org/10.1016/j.actamat.2004.04.035

[6] Murty, B.S., Kori, S.A. and Chakraborty, M. (2002) Grain Refinement of Aluminium and Its Alloys by Heterogeneous Nucleation and Alloying. International Materials Reviews, 47, 1-29. http://dx.doi.org/10.1179/095066001225001049

[7] Quested, T.E. and Greer, A.L. (2005) Grain Refinement of Al Alloys: Mechanisms Determining As-Cast Grain Size in Directional Solidification. Acta Materialia, 53, 4643-4653. http://dx.doi.org/10.1016/j.actamat.2005.06.018

[8] Ding, H., Li, H. and Liu, X. (2009) Different Elements-Induced Destabilisation of TiC and Its Application on the Grain Refinement of Mg-Al Alloys. Alloys and Compounds, 485, 285-289. http://dx.doi.org/10.1016/j.jallcom.2009.06.091

[9] Nikitin, V.I., Wanqi, J.I.E., Kandalova, E.G., Makarenko, A.G. and Yong, L. (2000) Preparation of Al-Ti-B Grain Refiner by Shs Technology. Scripta Materialia, 42, 561-566. http://dx.doi.org/10.1016/S1359-6462(99)00390-5

[10] Kunnam, P. and Limmaneevichitr, C. (2008) Effect of Process Parameters on Morphology and Grain Refinement Efficiency of $\mathrm{TiAl}_{3}$ and $\mathrm{TiB}_{2}$ in Aluminium Casting. Journal of Materials Science \& Technology, 24, 54-56.

[11] Sigworth, G.K. (1984) Method for Grain Refinement of High Strength Aluminum Casting Alloys. Metallurgical Transactions A, 15, 195-204.

[12] Banerji, A. and Reif, W. (1985) Al-6\% Ti-1.2\% C Master Alloy. Metallurgical Transactions A, 16, 2065-2068.

[13] Prasad, K.V.S. (1997) Development of Fast Acting and Long Lasting Grain Refiner (Al-5Ti-1B) for Aluminium and Its Alloys. Ph.D. Thesis, Indian Institute of Technology, India.

[14] Peijie, L., Kandalova, E.G., Makarenko, A.G., Nikitin, V.I., Zhanga, Y. and Luts, A.R. (2004) SHS Process and Structure Formation of Al-Ti-B Grain Refiner Made with the Use of Fluxes. Materials Letters, 58, 1861-1864.

[15] Maxwell, I. and Hellawell, A. (1975) A Simple Model for Grain Refinement during Solidification. Actametallurgica, 23, 229-237. http://dx.doi.org/10.1016/0001-6160(75)90188-1

[16] Liu, X.F., Wang, Z.Q., Zhang, Z.G. and Bian, X.F. (2002) The Relationship between Microstructures and Refining Performances of Al-Ti-C Master Alloys. Materials Science and Engineering A, 332, 70-74. http://dx.doi.org/10.1016/S0921-5093(01)01751-8

[17] Nie, J., Ma, X., Ding, H. and Liu, X. (2009) Microstructure and Grain Refining Performance of a New Al-Ti-C-B Master Alloy. Alloys and Compounds, 486, 185-190. http://dx.doi.org/10.1016/j.jallcom.2009.06.190

[18] Kori, S.A., Murty, B.S. and Chakraborty, M. (2000) Development of an Efficient Grain Refiner for Al-7Si Alloy. Materials Science and Engineering A, 280, 58-61. http://dx.doi.org/10.1016/S0921-5093(99)00656-5

[19] Zhang, Z., Watanabe, Y., Kim, I., Liu, X. and Bian, X. (2005) Microstructure and Refining Performance of an Al-5Ti0.25C Refiner before and after Equal-Channel Angular Pressing. Metallurgical and Materials Transactions A, 36, 837-844.

[20] Banerji, A. and Reif, W. (1986) Development of Al-Ti-C Grain Refiners Containing TiC. Metallurgical Transactions A, 17, 2127-2137. 
Scientific Research Publishing (SCIRP) is one of the largest Open Access journal publishers. It is currently publishing more than 200 open access, online, peer-reviewed journals covering a wide range of academic disciplines. SCIRP serves the worldwide academic communities and contributes to the progress and application of science with its publication.

Other selected journals from SCIRP are listed as below. Submit your manuscript to us via either submit@scirp.org or Online Submission Portal.
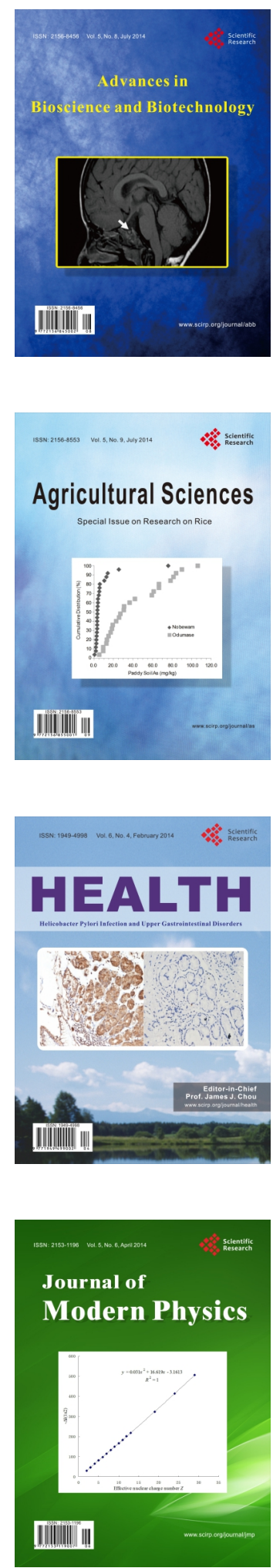
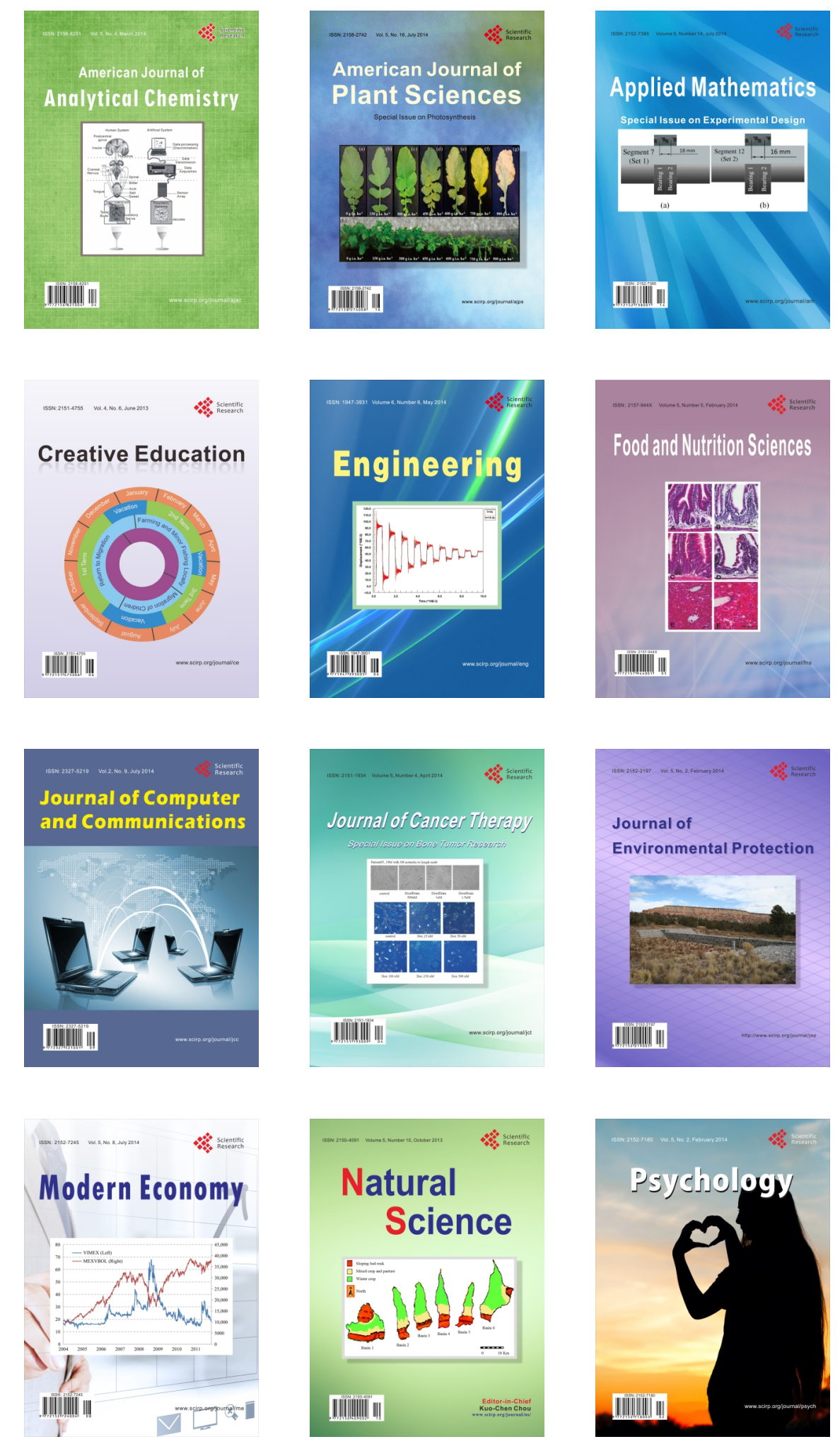